
\title{
25 Research Soure \\ Identification of Safe Channels for Screws in the Anterior Pelvic Ring Fixation System
}

Lin Liu ( $\square$ liulinmyone@163.com )

University of Chinese Academy of Sciences Shenzhen Hospital

Shicai Fan

Third Affiliated Hospital of Southern Medical University

Donggui Zeng

University of Chinese Academy of Sciences Shenzhen Hospital

Hui Song

University of Chinese Academy of Sciences Shenzhen Hospital

\section{Letian Zeng}

University of Chinese Academy of Sciences Shenzhen Hospital

\section{Xiangyuan Wen}

Third Affiliated Hospital of Southern Medical University

Dadi Jin

Third Affiliated Hospital of Southern Medical University

\section{Research Article}

Keywords: Anterior pelvic ring fixation system, Pelvic fracture, Safe channel, Minimally invasive

Posted Date: April 19th, 2022

DOI: https://doi.org/10.21203/rs.3.rs-1267646/v2

License: (c) (i) This work is licensed under a Creative Commons Attribution 4.0 International License.

Read Full License 


\section{Abstract}

Background: There have been few studies on insertion of fixation screws for the anterior pelvic ring system. Objective: To identify safe channels for fixation screws in the anterior pelvic fixation system. I

Methods: Screw insertion was simulated into a total of 40 pelvic finite element models as well as 16 fresh pelvic specimens and the channel parameters were measured.

Results: Finite elements (male, female): screws in ilium: length $114.4 \pm 4.1$ and $107.6 \pm 8.3 \mathrm{~mm}$, respectively; diameter $11.7 \pm 0.5$ and $10.0 \pm 0.6 \mathrm{~mm}$, distance between screw and anterior inferior iliac spine: $5.5 \pm 1.0$ and $5.6 \pm 1.0 \mathrm{~mm}$, angle of coronal plane $55.8 \pm 2.4$ degrees and $50.6 \pm 3.1$ degrees, angle of sagittal plane $26.6 \pm 1.0$ degrees and $24.5 \pm 1.9$ degrees and angle of horizontal plane $64.9 \pm 3.7$ and $58.1 \pm 3.1$. Screws in pubis: length $47.0 \pm 2.0$ and $39.8 \pm 3.9 \mathrm{~mm}$, diameter $7.1 \pm 0.4$ and $6.1 \pm 0.4$ $\mathrm{mm}$. Specimens (male, female): distance between screw and anterior inferior iliac spine: $5.5 \pm 0.5$ and 5.6 $\pm 0.7 \mathrm{~mm}$, angle of coronal plane $55.9 \pm 1.3$ degrees and $50.7 \pm 1.5$ degrees, angle of sagittal plane $26.7 \pm$ 0.5 degrees and $24.1 \pm 0.9$ degrees and angle of horizontal plane $64.8 \pm 0.6$ degrees and $58.8 \pm 0.8$ degrees. Comparison between female and male in each group: differences in distances between screws and anterior inferior iliac spine and median line of symphysis pubis $(P>0.05)$ were not statistically significant; differences in the remaining parameters were statistically significant $(P<0.05)$.

Conclusions: If surgeons payed attention to sex differences, select screws of appropriate diameter and length, and hold the insertion position and direction, screws in the anterior pelvic ring fixation system could be safely inserted.

\section{Background}

With the development of minimally-invasive technologies for the treatment of pelvic fracture, good outcomes for fractures of the anterior pelvic ring treated with a subcutaneous fixator [1-2] or INFIX technology $[3,4]$ have been reported. However, the best way to insert the fixation screws in the fixation system, one of the key technical points of the method, has rarely been reported. In this study, the parameters of safe screw channels were investigated using the finite element method and the traditional anatomic method to provide the anatomical basis for best clinical practice.

\section{Materials And Methods}

\section{Materials}

We used original image data of normal pelvises scanned with a Toshiba/Aquilion 64-row 128-slice spiral CT (Toshiba, Japan) in the Third Affiliated Hospital of Southern Medical University or a Siemens Somatom Definition Flash dual-source 64-row 128-slice CT (Siemens AG, Erlangen, Germany) in the University of the Chinese Academy of Sciences, Shenzhen Hospital between January 2017 and January 2020, comprising 20 males and 20 females, aged 20-65 years with a mean age of 42 years. 
In addition, the Department of Anatomy of Southern Medical University provided 16 fresh and cold adult pelvic specimens (10 male specimens and six female specimens, aged 25-66 years with a mean age of 43.5 years), which were free of fractures, tumors, malformations and obvious osteoporosis as ascertained by visual observation and CT examination. Each of the specimens was a complete pelvis including the L5 vertebral column.

\section{Finite Element Research Method}

CT image data were imported into Mimics 21.0 (Materialise, Leuven, Belgium) to create finite element pelvic model images $[5,6]$ and a cylinder was created to simulate the insertion of a fixation screw from the superior margin of the anterior inferior iliac spine to the posterior inferior iliac spine and another screw insertion in the para-pubic region perpendicular to the surface of the pubis. The axis of each cylinder was defined as the best approach and the radius of each cylinder was adjusted, from small to large.

Observations were taken from the coronal plane, sagittal plane and horizontal plane and in these three 2D planes, if the cylinder protruded either side of the bone cortex, the face where this point was located was defined as the narrowest point of the fixation screw channel [7, 8]. If the screws did not break through the cortical bone or out of the joint, parameters such as the diameter and length of the cylinder, distance from the anterior inferior iliac spine or the symphysis pubis, and angles between the screws and coronal, sagittal and horizontal planes of the human body were measured (Fig. 1).

\section{Specimen Study Methods}

Several leads with a diameter of $2.5 \mathrm{~mm}$ were inserted into the anterior inferior iliac spine approximately $5 \mathrm{~mm}$ from the superior margin of the anterior inferior iliac spine [9] to determine the optimal insertion point and placement position of the screws, and a screw channel between the internal and external plates of the ilium whose depth should be measured was created. Then a titanium alloy universal fixation screw of the anterior ring (Xiamen Double Medical Co., Ltd., Xiamen, China) of $7.5 \mathrm{~mm}$ in diameter and 60-90 $\mathrm{mm}$ in length was inserted with the screw tail exposed $10-15 \mathrm{~mm}$ outside the bone. In the $1 \mathrm{~cm}$ area between the pubis and the symphysis pubis, a universal fixation screw of the anterior ring with a diameter of $45 \mathrm{~mm}$ and a length of 35-45 $\mathrm{mm}$ was inserted and according to our observation, the position of the screw was correct with no protrusion from the bone cortex. The screw was then removed and a Kirschner wire with diameter of $2.5 \mathrm{~mm}$ was inserted to measure the distance between the screw and the anterior inferior iliac spine and the symphysis pubis, as well as the angle between the screws in the ilium and the anatomic planes (Fig. 2).

\section{Statistical Methods}

SPSS 21.0 software (IBM SPSS Statistics for Windows, Armonk, NY, USA) was used for statistical analysis of the data. All measurement data are expressed as $\nabla x \pm s$ and compared by paired $t$-test. $A$ 


\section{Results}

\section{Experimental results obtained by the finite element method}

The maximum length and diameter of the screws, the distance between the screw in the ilium and the anterior inferior iliac spine, and the distance between the screw in the pubis and the symphysis pubis are shown in Table 1. Left-and-right comparison showed that differences between the data of the same sex $(P>0.05)$ were not statistically significant. Ignoring differences between data from left and right side screws in the ilium of males and screws in the ilium of females: with maximum length of $114.4 \pm 4.1 \mathrm{~mm}$ and $107.6 \pm 8.3 \mathrm{~mm}$, respectively, and maximum diameter of $11.7 \pm 0.5$ and $10.0 \pm 0.6 \mathrm{~mm}$, the distance from the symphysis pubis was $5.5 \pm 1.0$ and $5.6 \pm 1.0 \mathrm{~mm}$. In comparison between males and females, the differences in the length and diameter of the screws were statistically significant $(P<0.05)$ (Fig. 3a, b) but the differences in distance between the screws and the symphysis pubis were not statistically significant $(P>0.05)$ (Fig. 3c). Regarding screws in the pubis of females and males: with maximum lengths of $47.0 \pm 2.0$ and $39.8 \pm 3.8 \mathrm{~mm}$, maximum diameters of $7.1 \pm 0.4$ and $6.1 \pm 0.4 \mathrm{~mm}$, the distances between the screws and the symphysis pubis were $10.1 \pm 0.7$ and $10.1 \pm 0.8 \mathrm{~mm}$ respectively. When compared between males and females, the differences in the length and diameter of the screws were statistically significant $(P<0.05)(F i g .3 \mathrm{~d}, \mathrm{e})$ and the differences in distance between the screws and the symphysis pubis were not statistically significant $(P>0.05)$ (Fig. 3f).

Table 1

The length, diameter and position parameters of screws $(\mathrm{mm}, \mathrm{n}=20)$

\begin{tabular}{|lllll|}
\hline Parameters & Male & \multicolumn{3}{c|}{ Female } \\
\cline { 2 - 5 } & Left & Right & Left & \multicolumn{2}{c|}{ Right } \\
\hline Length of screw in ilium & $114.6 \pm 4.2$ & $114.3 \pm 4.0$ & $107.7 \pm 9.7$ & $107.5 \pm 7.0$ \\
\hline Diameter of screw in ilium & $11.7 \pm 0.5$ & $11.7 \pm 0.5$ & $10.0 \pm 0.6$ & $10.0 \pm 0.6$ \\
\hline $\begin{array}{l}\text { Distance between screw and } \\
\text { anterior inferior iliac spine }\end{array}$ & $5.5 \pm 1.0$ & $5.5 \pm 1.0$ & $5.6 \pm 0.9$ & $5.6 \pm 1.2$ \\
\hline $\begin{array}{l}\text { Length of screw in pubis } \\
\text { Diameter of screw in pubis }\end{array}$ & $46.9 \pm 1.1$ & $47.2 \pm 2.6$ & $39.9 \pm 3.2$ & $39.8 \pm 4.5$ \\
\hline $\begin{array}{l}\text { Distance between screw } \\
\text { and symphysis pubis }\end{array}$ & $10.1 \pm 0.7$ & $10.1 \pm 0.7$ & $10.1 \pm 0.7$ & $10.1 \pm 0.9$ \\
\hline $\begin{array}{l}\text { Left-and-right comparison of same-sex data indicated that the differences were not statistically } \\
\text { significant. }\end{array}$ & & & & \\
\hline
\end{tabular}


The angle between the screws in the ilium and the coronal, sagittal and horizontal planes of the human body are shown in Table 2. The left-and-right comparison showed that differences in same sex data were not statistically significant $(P>0.05)$. Ignoring the differences between data of left and right sides, the included angles between screws in the ilium and the coronal plane were $55.8 \pm 2.4$ and $50.6 \pm 3.1$ degrees, and in the sagittal plane were $26.6 \pm 1.0$ and $24.5 \pm 1.9$ degrees, while those in the horizontal plane were $64.9 \pm 3.7$ and $58.1 \pm 3.1$ degrees. The differences in the included angles between males and females were statistically significant $(P<0.05)$ (Fig. 3g-i).

Table 2

Orientation parameters of the screw in the ilium (degrees, $\mathrm{n}=20$ )

\begin{tabular}{|lllll|}
\hline Parameters & Male & \multicolumn{2}{c|}{ Female } \\
\hline & Left & Right & Left & \multicolumn{1}{c|}{ Right } \\
\hline Angle of coronal plane & $55.8 \pm 2.4$ & $55.7 \pm 2.6$ & $50.9 \pm 3.6$ & $50.3 \pm 2.4$ \\
\hline Angle of sagittal plane & $26.6 \pm 1.2$ & $26.6 \pm 0.9$ & $24.6 \pm 1.9$ & $24.3 \pm 1.9$ \\
\hline Angle of horizontal plane & $64.6 \pm 1.2$ & $64.9 \pm 4.4$ & $58.1 \pm 3.3$ & $58.0 \pm 3.0$ \\
\hline $\begin{array}{l}\text { The left-and-right comparison showed that none of the differences in any parameters were } \\
\text { statistically significant }(P>0.05) .\end{array}$ & & & \\
\hline
\end{tabular}

\section{Results Of The Study Of Pelvic Specimens}

The diameters of the screws in the ilium and pubis were $7.5 \mathrm{~mm}$ and $4.5 \mathrm{~mm}$ respectively, and the screws in the pubis were inserted perpendicular to the upper surface of the pubis. The position and length of screws are shown in Table 3 and the angles between screws in the ilium and the anatomic planes are shown in Table 4. The left-and-right comparison showed that differences of same-sex data were not statistically significant $(P>0.05)$. Ignoring left-and-right differences of the data, the lengths of screws in the ilium in males and females were $85.5 \pm 3.6$ and $76.7 \pm 4.9 \mathrm{~mm}$ and the lengths of screws in the pubis were $41.5 \pm 2.4$ and $35.0 \pm 0.0 \mathrm{~mm}$. The difference between females and males was statistically significant $(P<0.01)$ (Fig. 4a,c). In males and females, the distances between the screws and the anterior inferior iliac spine were $5.5 \pm 0.5$ and $5.6 \pm 0.7 \mathrm{~mm}$ and the distances between the screws and the symphysis pubis were $10.4 \pm 0.4$ and $10.4 \pm 0.5 \mathrm{~mm}$. The differences between females and males were not statistically significant $(P>0.05)$ (Fig. $4 b, d)$. In females and males, the included angles between screws in the ilium and the coronal plane were $55.9 \pm 1.3$ and $50.7 \pm 1.5$ degrees, the included angles between screws in the ilium and in the sagittal plane were26.7 \pm 0.5 degrees and $24.1 \pm 0.9$ degrees, and the included angles between screws in the ilium and in the horizontal plane were $64.8 \pm 0.6$ degrees and $58.8 \pm 0.8$ degrees respectively. The differences between females and males were statistically significant $(\mathrm{P}<0.01)$ (Fig. 4e-g). 
Table 3

The position parameters of screws in pelvic specimens ( $\mathrm{mm}$; males 10 , females 6 )

\begin{tabular}{|c|c|c|c|c|}
\hline \multirow[t]{2}{*}{ Parameters } & \multicolumn{2}{|l|}{ Male } & \multicolumn{2}{|c|}{ Female } \\
\hline & Left & Right & Left & Right \\
\hline $\begin{array}{l}\text { Distance between screw and anterior inferior } \\
\text { iliac spine }\end{array}$ & $\begin{array}{l}5.5 \pm \\
0.5\end{array}$ & $5.4 \pm 0.6$ & $5.6 \pm 0.7$ & $5.6 \pm 0.8$ \\
\hline Distance between screw and symphysis pubis & $\begin{array}{l}10.4 \pm \\
0.4\end{array}$ & $10.4 \pm 0.5$ & $10.3 \pm 0.5$ & $10.5 \pm 0.5$ \\
\hline Length of screw in ilium & $\begin{array}{l}85.5 \pm \\
3.7\end{array}$ & $85.5 \pm 3.7$ & $76.7 \pm 5.2$ & $76.7 \pm 5.2$ \\
\hline Length of screw in pubis & $\begin{array}{l}41.5 \pm \\
2.4\end{array}$ & $41.5 \pm 2.4$ & $35.0 \pm 0.0$ & $35.0 \pm 0.0$ \\
\hline
\end{tabular}

Table 4

The orientation parameters of screws in the ilium (degrees; 10 males, 6 females)

\begin{tabular}{lcccc} 
Parameters & \multicolumn{2}{c}{ Male } & \multicolumn{2}{c}{ Female } \\
& \multicolumn{2}{c}{ Left } & Right & \multicolumn{2}{c}{ Left } & Right \\
Angle of coronal plane & $55.9 \pm 1.3$ & $55.9 \pm 1.4$ & $50.8 \pm 1.6$ & $50.7 \pm 1.5$ \\
Angle of sagittal plane & $26.8 \pm 0.5$ & $26.6 \pm 0.5$ & $24.1 \pm 0.9$ & $24.0 \pm 0.9$ \\
Angle of horizontal plane & $64.8 \pm 0.6$ & $64.7 \pm 0.5$ & $58.7 \pm 0.8$ & $58.8 \pm 0.8$ \\
$\begin{array}{l}\text { Left-and-right comparison showed differences in same-sex data were not statistically significant }(P> \\
\text { l.05). }\end{array}$
\end{tabular}

\section{Validation Of The Finite Element Model}

Differences in the distance between the screw in the ilium, that in the anterior inferior iliac spine and that in the symphysis pubis, and the included angles between the screws in the ilium and the anatomic planes between the finite element model group and the pelvic specimen group of the same sex were not statistically significant $(P>0.05)$ (Fig. 5,6$)$. These results show that the finite element model developed in this study was validated in term of the channel parameters of the screw.

\section{Discussion}


In previous studies, research on the optimal channels for pelvic screws was mainly based on traditional autopsy measurements, because they were based on actual anatomy, cannot be surpassed by other testing methods [10]. However this approach is restricted by many factors such as source, repeatability, and man-made measurement errors [11, 12]. In recent years, Mimics software has become commonly used in digital anatomical research, which transforms bones and soft tissues into virtual 3D models using CT or MRI scanning data. Based on these 3D models, anatomical measurements, simulated operations, and prosthesis design can then be carried out. In comparison with traditional anatomy and imaging studies, it has the advantages of low cost, high repeatability, comprehensive information acquisition and good reliability, high measurement precision and more accurate experimental results, and avoids the disadvantages of the traditional autopsy method, such as limited resources, difficult operation and inaccurate results [14]. In this study, a 3D finite element model of the pelvis was established using Mimics software to simulate the internal fixation system with screws inserted. The maximum length, diameter and angle between the screw and the anatomic axis were measured. At the same time, internal screws were inserted into a few pelvic specimens and the parameters of each channel were measured to verify the accuracy of data obtained by the finite element method. The differences in the distance between the screw and the anterior inferior iliac spine and the symphysis pubis, and the included angles between the screws in the ilium and the anatomic planes between the finite element models and pelvic specimens of the same sex were not statistically significant, indicating that the safe channel parameters obtained by the finite element model were accurate.

The main complications of repairing fractures of the anterior pelvic ring with a fixation system include injury to the lateral femoral cutaneous nerve and femoral nerve, with an incidence rate ranging from $4 \%$ as reported by Cole et al. [15] to $32 \%$, as reported by Kuttner et al. [16]. Hesse et al. [17] reported six cases of femoral nerve injury. Vaidya [18] believed that the most common complications were heterotopic ossification (35\% incidence rate) and stimulation of the lateral femoral cutaneous nerve (incidence rate of $30 \%$ ). The reported incidence of complications in the application of the anterior pelvic ring fixation system varies greatly, and consequently there have been some studies of the safety of this system. Validya et al. provided clear guidance on how to safely insert the fixation system, requiring that the pedicle screw cap should be 1.5-5.0 cm from the bone surface, the connective bar should be located in the bikini line through the subcutaneous passage [19], and the long connective bar should be cut off. Merriman et al. [20] considered that the average distance between the connective bar and the vascular bundle should be greater than $2.2 \mathrm{~cm}$ to prevent compression of the vascular nerve. Apivatthakakul et al. [21] argued that the femoral nerve was at the highest risk of being compressed by the connective bar, and suggested that a universal screw should be used for fixation with some space on the screw, and that the surface of the ilium and both ends of the connective bar should be as short as possible to minimize injury to the lateral femoral cutaneous nerve.

At present, studies on the safety of the internal fixation system have mainly focused on the distance of the fixation bar and the fixation screw from the bone surface and its distance from the main anatomical structures, but there have been few anatomical studies on fixation screw insertion. Safe and effective insertion of the fixation screws is the first step of a successful operation. In this study, the safe channels 
for inserted screws were studied using the finite element method and the traditional anatomical method to provide an anatomical basis for rapid and safe insertion of fixation screws in the clinic.

In the study, the differences in the maximum length and diameter of screws in the ilium and pubis, the angles between the ilium screw and the anatomic planes in males and females were statistically significant, while the differences in the distances between the screw and the anterior inferior iliac spine and the symphysis pubis in males and females were not statistically significant. It can be seen that due to the difference between males and females, and the shape of the pelvis, the safe length, diameter and included angles between the anatomical faces and the screws differed between males and females. In the common anterior fixation system used in the clinic, fixation screws used in the ilium had a diameter of $7.5 \mathrm{~mm}$ and a length of $60-100 \mathrm{~mm}$, while the fixation screws used in the pubis had a diameter of 4.5 $\mathrm{mm}$ and a length of 35-45 $\mathrm{mm}$. In this study, the maximum diameter and the maximum length of the screws in the ilium in males and females were larger than $10 \mathrm{~mm}$ and $100 \mathrm{~mm}$, respectively, the maximum diameter and the maximum length of the screws in the pubis in males and females were larger than $6 \mathrm{~mm}$ and $35 \mathrm{~mm}$, and the length and diameter of screws inserted into males were greater than that of those inserted into females. Therefore, in clinical practice, screws in the ilium can be $7.5 \mathrm{~mm}$ in diameter for both men and women, screws with a length of 70-100 mm can be used for men and screws with a length of $60-90 \mathrm{~mm}$ can be used for women. Screws in the pubis can have a diameter of $4.5 \mathrm{~mm}$ for both men and women and screws with a length of 35-45 $\mathrm{mm}$ can be used for men while screws 35 $\mathrm{mm}$ in length can be used for women. Safe insertion of the screws dependsed on correct position and orientation. According to our research results, there were no differences between males and females with regard to screw insertion points, which were approximately $5 \mathrm{~mm}$ above the anterior inferior iliac spine, and approximately $10 \mathrm{~mm}$ outside the midline of the symphysis pubis. The screws in the pubis needed to be inserted from top to bottom and perpendicular to the upper surface of the pubis. However, due to the irregular anatomical shape of the ilium, it was difficult to insert the screws safely, and also due to the difference in the angles between the screws and the anatomical surfaces between men and women, attention should be paid to gender differences during the operation. According to the study results, screws in the ilium could be safely inserted when the angles between the screw and the coronal, sagittal and horizontal planes are approximately 56 degrees, 26 degrees and 65 degrees, respectively, in males and 51 degrees, 25 degrees and 59 degrees in females. The above steps can be used to guide the rapid and safe insertion of fixation screws in the clinic, avoid the risks of a screw protruding from the cortex or the joint and damaging the pelvic organs, reduce the number of $X$-ray fluoroscopies and shorten the operation time.

\section{Deficiencies Of The Study}

In the study, ideal conditions for screw insertion were simulated and the thickness of the iliac and pubic cortex may differ from the real situation during simulated screw insertion, with the result that the length and maximum diameter of the simulated screws may differ from screws actually inserted. 
The actual insertion point and orientation of the screws may differ from those of the normal pelvis due to displacement of a pelvic fracture and changes of body position.

\section{Future Study}

Our further studies will focus on clinical application of pelvic fracture treatment using an internal fixator system. Their clinical effects will be investigated.

\section{Conclusions}

The screws in the ilium of the anterior pelvic ring fixation system (male, female): had a maximum length of $114.44 \pm 4.07$ and $107.59 \pm 8.34 \mathrm{~mm}$, maximum diameter of $11.71 \pm 0.52$ and $10.01 \pm 0.55 \mathrm{~mm}$, distance between screw and anterior inferior iliac spine of $5.51 \pm 0.98$ and $5.57 \pm 1.01 \mathrm{~mm}$, angle between the screw and the coronal plane of $55.79 \pm 2.44$ degrees and $50.62 \pm 3.05$ degrees and angle between the screw and sagittal plane of $26.58 \pm 1.0$ degrees and $24.45 \pm 1.87$ degrees, angle between the screw and horizontal plane of $64.88 \pm 3.67$ degrees and $58.05 \pm 3.10$ degrees; screws in pubis (male, female): maximum length of $47.02 \pm 1.96 \mathrm{~mm}$ and $39.81 \pm 3.84 \mathrm{~mm}$, maximum diameter of $7.12 \pm 0.38$ and $6.12 \pm$ $0.37 \mathrm{~mm}$ and distance between screw and symphysis pubis of $10.11 \pm 0.71$ and $10.06 \pm 0.82 \mathrm{~mm}$. According to the above data, in order to safely insert screws of the anterior pelvic ring fixation superior margin of the anterior inferior iliac spine and the symphysis pubis, attention should be paid to gender differences, selection of screws of the appropriate diameter and length, and holding the position and orientation.

\section{Abbreviations}

INFIX: Internal fixator; CT: Computed tomography; MRI: Magnetic Resonance Imaging; 3D: Three Dimensions.

\section{Declarations}

\section{Acknowledgements}

We thank the Department of Human Anatomy of Southern Medical University for supporting the experiment. We thank International Science Editing ( http://www.internationalscienceediting.com ) for editing this manuscript.

Authors' contributions Lin Liu and Shicai Fan developed the study design, performed the experiment, data analysis, and writing the manuscript. Xiangyuan Wen, Hui Song and Letian Zeng performed the experiment, data collection, and data interpretation. Donggui Zeng, and Dadi Jin analyzed and interpreted the data. All authors read and approved the final manuscript. 


\section{Funding}

This work was supported by Special fund for economic development of Guangming District, Shenzhen 邓2020R01024『

\section{Availability of data and materials}

The datasets used and analyzed in the study are available from the corresponding author on request to the corresponding author.

\section{Ethics approval and consent to participate}

The study was approved by the Institutional Review Board (approval number: LL-KT-2020145) of University of Chinese Academy of Sciences Shenzhen Hospital.

\section{Consent for publication}

Not applicable.

\section{Competing interests}

The authors declare that they have no competing interests.

\section{Author details}

1.Orthopedic Trauma, University of Chinese Academy of Sciences Shenzhen Hospital, Guangdong, Shenzhen, P. R. China. 2.The Third Affiliated Hospital, Southern Medical University, Guangzhou, Guangdong, P. R. China.

\section{References}

1. Cole PA, Gauger EM, Anavian J, Ly TV, Morgan RA, Heddings AA. Anterior pelvic external fixator versus subcutaneous internal fixator in the treatment of anterior ring pelvic fractures. $J$ Orthop Trauma. 2012;26:269-7. doi.org/10.1097/BOT.0b013e3182410577.

2. Hiesterman TG, Hill BW, Cole PA. Surgical technique: a percutaneous method of subcutaneous fixation for the anterior pelvic ring: the pelvic bridge. Clin Orthop Relat Res. 2012;470:2116-23. doi.org/10.1007/ s11999-012-2341-4.

3. Vaidya R, Colen R, Vigdorchik J, Tonnos F, Sethi A. Treatment of unstable pelvic ring injuries with an internal anterior fixator and posterior fixation: initial clinical series. J Orthop Trauma. 2012;26:1-8. https://doi.org/10.1 097/BOT.0b013e318233b8a7.

4. Scherer, J., Tiziani, S., Sprengel, K. et al. Subcutaneous internal anterior fixation of pelvis fractureswhich configuration of the InFix is clinically optimal? -a retrospective study. International Orthopaedics(SICOT) 43, 2161-2166 (2019). https://doi.org/10.1007/s00264-018-4110-9. 
5. Wu T, Ren X, Cui Y, et al. Biomechanical study of three kinds of internal fixation for the treatment of sacroiliac joint disruption using biomechanical test and finite element analysis. J Orthop Surg Res. 2018;13(1):152. Published 2018 Jun 19. doi:10.1186/s13018-018-0858-2.

6. Hu P, Wu T, Wang HZ, et al. Influence of different boundary conditions in finite element analysis on pelvic biomechanical load transmission. Orthop Surg. 2017;9(1):115-122. doi:10.1111/os.12315.

7. Shin JK, Lim BY, Goh TS, et al. Effect of the screw type (S2-alar-iliac and iliac), screw length, and screw head angle on the risk of screw and adjacent bone failures after a spinopelvic fixation technique: A finite element analysis. PLoS One. 2018;13(8):e0201801. Published 2018 Aug 16. doi: 10.1371/journal.pone.0201801.

8. Li W, Zhao F, Sun Z, et al. Digital anatomy to improve screw insertion techniques for plate-screw fixation of the pubic body. Biomed Res Int. 2018;2018:4690879. Published 2018 Dec 12. doi:10.1155/2018/4690879.

9. Gardner MJ, Mehta S, Mirza A, Ricci WM. Anterior pelvic reduction and fixation using a subcutaneous internal fixator. J Orthop Trauma. 2012 May;26(5):314-21. doi: 10.1097/BOT.0b013e318220bb22. PMID: 22048189.

10. Ebraheim NA, Xu R, Biyani A, Benedetti JA. Anatomic basis of lag screw placement in the anterior column of the acetabulum. Clin Orthop Relat Res. 1997 Jun;(339):200-5. doi: 10.1097/00003086199706000-00028. PMID: 9186221.

11. Dienstknecht T, Müller M, Sellei R, et al. Screw placement in percutaneous acetabular surgery:gender differences of anatomical landmarks in a cadaveric study[J]. Int Orthop,2013,37(4):673-679. doi:10.1007/s00264-012-1740-1.

12. García JM, Doblaré M, Seral B, Seral F, Palanca D, Gracia L. Three-dimensional finite element analysis of several internal and external pelvis fixations. J Biomech Eng. 2000 Oct;122(5):516 - 22. doi: 10.1115/1.1289995. PMID: 11091954.

13. Liu XM, Pan CW, Wang GD, Cai XH, Chen L, Meng CF, Huang JC. Finite element analysis of the stability of combined plate internal fixation in posterior wall fractures of acetabulum. Int $\mathrm{J}$ Clin Exp Med. 2015 Aug 15;8(8):13393-7. PMID: 26550272; PMCID: PMC4612957.

14. Yildirim AO, Alemdaroglu KB, Yuksel HY, Öken ÖF, Ucaner A. Finite element analysis of the stability of transverse acetabular fractures in standing and sitting positions by different fixation options. Injury. 2015 Jul;46 Suppl 2:S29-35. doi: 10.1016/j.injury.2015.05.029. Epub 2015 May 28. PMID: 26028425.

15. Cole PA, Dyskin EA, Gilbertson JA. Minimally-invasive fixation for anterior pelvic ring disruptions. Injury. 2015 Sep;46 Suppl 3:S27-34. doi: 10.1016/S0020-1383(15)30008-5. PMID: 26458296.

16. Kuttner M,Klaiber A,Lorenz T,et al.The pelvic subcutaneous cross-over internal fixator[J]. Unfallchirurg,2009,112(7):661-669. https://doi.org/10.1007/s00113-009-1623-0.

17. Hesse D, Kandmir U, Solberg B, Stroh A, Osgood G, Sems SA, Collinge CA. Femoral nerve palsy after pelvic fracture treated with INFIX: a case series. J Orthop Trauma. 2015 Mar;29(3):138 - 43. doi: 10.1097/BOT.0000000000000193. PMID: 24983430. 
18. Vaidya R, Kubiak EN, Bergin PF, Dombroski DG, Critchlow RJ, Sethi A, Starr AJ. Complications of anterior subcutaneous internal fixation for unstable pelvis fractures: a multicenter study. Clin Orthop Relat Res. 2012 Aug;470(8):2124-31. doi: 10.1007/s11999-011-2233-z. PMID: 22219004; PMCID: PMC3392373.

19. Vaidya R, Oliphant B, Jain R, Nasr K, Siwiec R, Onwudiwe N, Sethi A. The bikini area and bikini line as a location for anterior subcutaneous pelvic fixation: an anatomic and clinical investigation. Clin Anat. 2013 Apr;26(3):392-9. doi: 10.1002/ca.22149. Epub 2012 Aug 24. PMID: 22927118.

20. Merriman DJ, Ricci WM, McAndrew CM, et al. Is application of an internal anterior pelvic fixator anatomically feasible?[J].Clin Orthop Relat Res,2012,470(8):2111-2115. doi:10.1007/s11999-0122287-6.

21. Apivatthakakul T, Rujiwattanapong N. "Anterior subcutaneous pelvic internal fixator (INFIX), Is it safe?" A cadaveric study. Injury. 2016;47(10):2077-80. https://doi.org/10.1016/j.injury.2016.08.006.

\section{Figures}

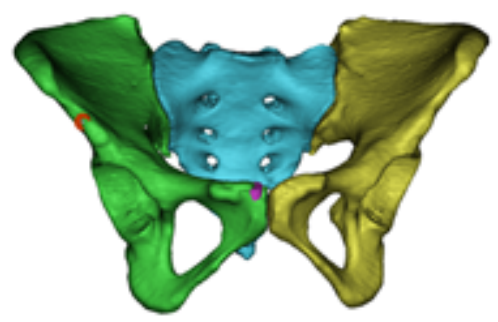

a

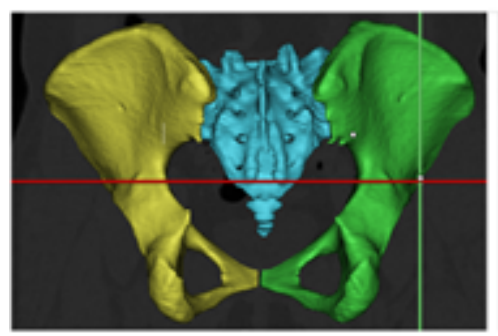

d

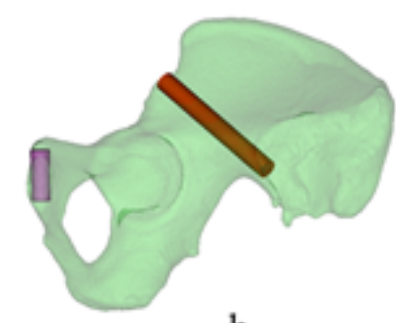

b

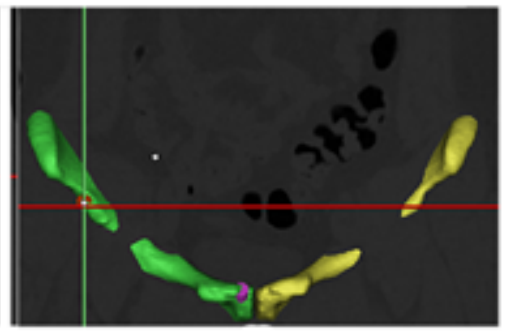

e

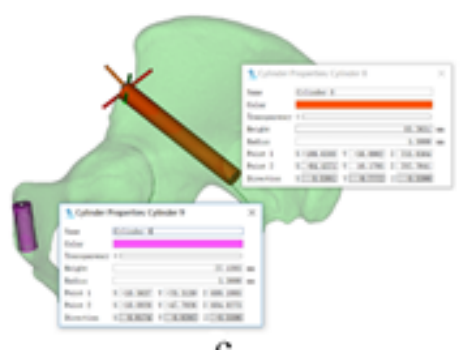

c

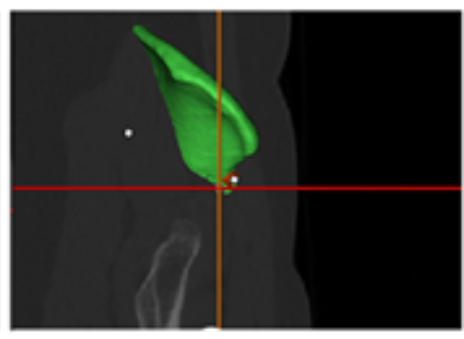

f

\section{Figure 1}

Model-simulated screw insertion and measurement; a: insertion position, b: insertion channel, c: parameter measurement, $d$ : observation in horizontal plane, e: observation in coronal plane, f: observation in sagittal plane.

\section{Figure 2}


Measurement of screw parameters in specimens; a: pelvis specimen, b: screw insertion, c: Kirschner wire insertion, d: distance measurement, e: length measurement, f: angle measurement.
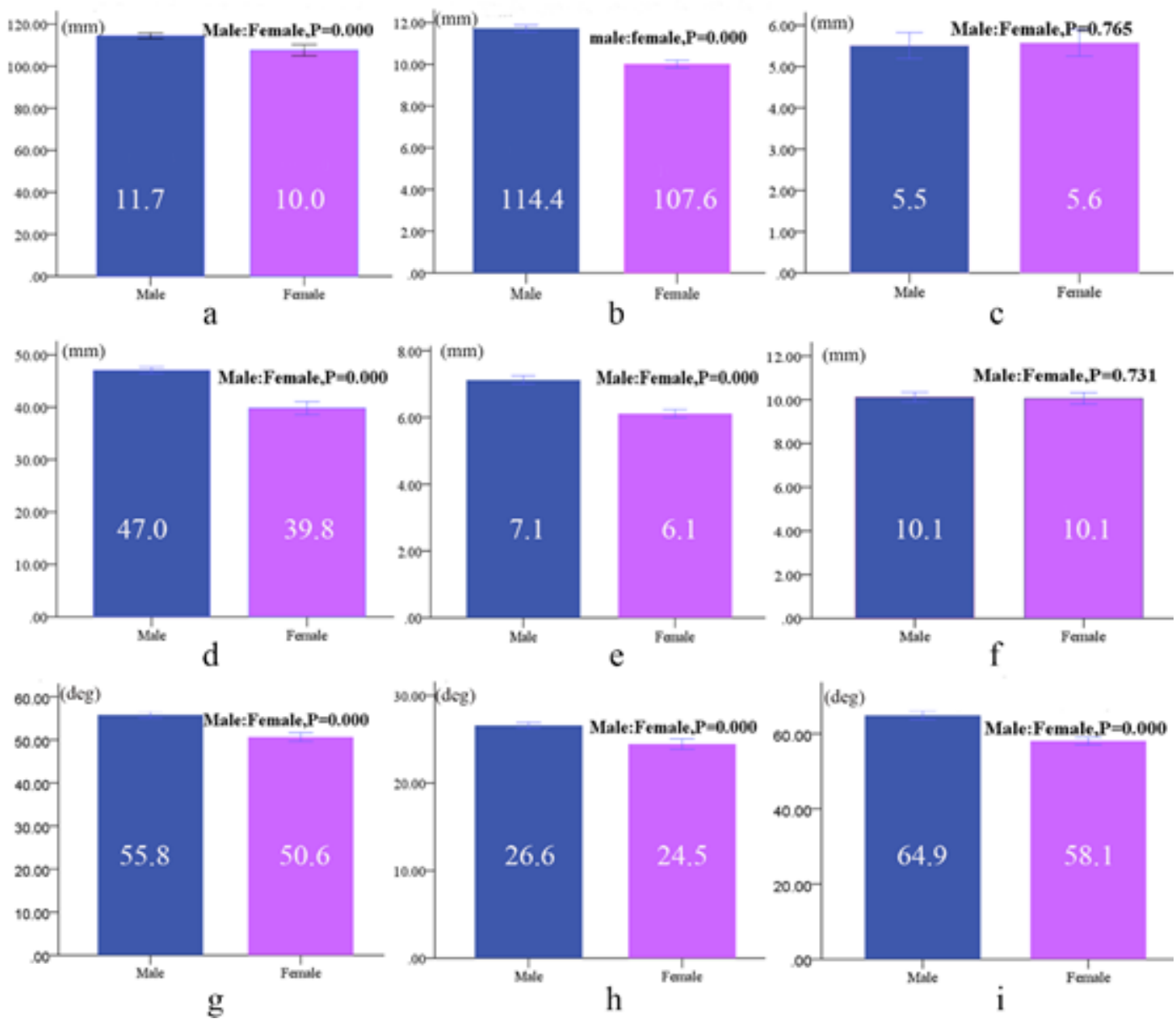

Figure 3

Parameters of screws in finite element model $(n=40)$; a: length of screw in ilium, b: diameter of screw in ilium, c: distance between screw and anterior inferior iliac spine, d: length of screw in pubis, e: diameter of screw in pubis and f: distance between screw and symphysis pubis, h: included angle between screw and coronal plane, i: included angle between screw and sagittal plane, g: included angle between screw and horizontal plane. 

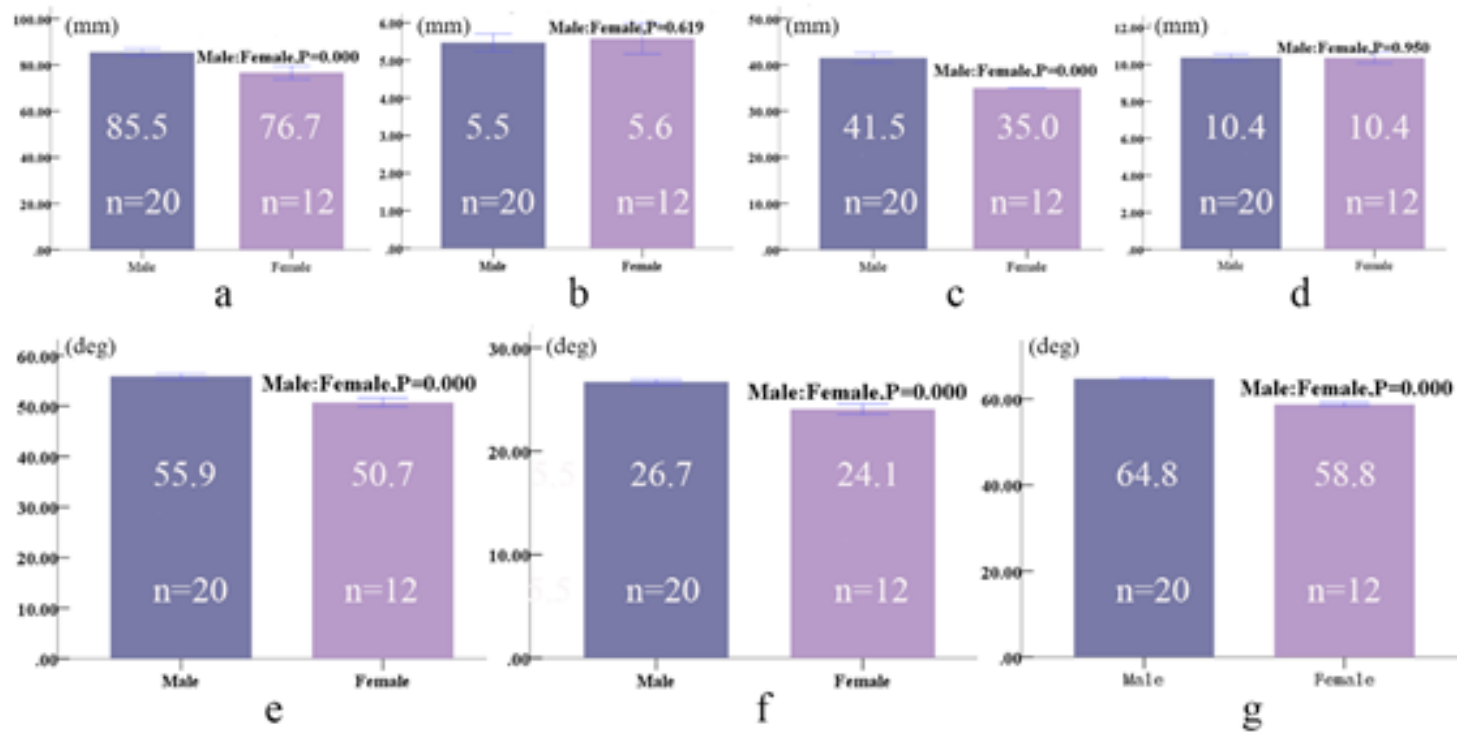

\section{Figure 4}

Parameters of screws in specimens (Male 20, Female 12); a: length of screw in ilium, b: distance between screw and anterior inferior iliac spine, c: length of screw in pubis, d: distance between screw and symphysis pubis, e: included angle between screw in ilium and coronal plane, $\mathrm{f}$ : included angle between screw and sagittal plane, g: included angle between screw and horizontal plane.

\section{Figure 5}

Comparison of parameters between finite element models analysis and pelvic specimens of males (Finite element model 40, Specimens 20); a: distance between the screw and the anterior inferior iliac spine, b: distance between screw and symphysis pubis, c: included angle between screw and coronal plane, $\mathrm{d}$ : included angle between screw and sagittal plane, e: included angle between screw and horizontal plane. 

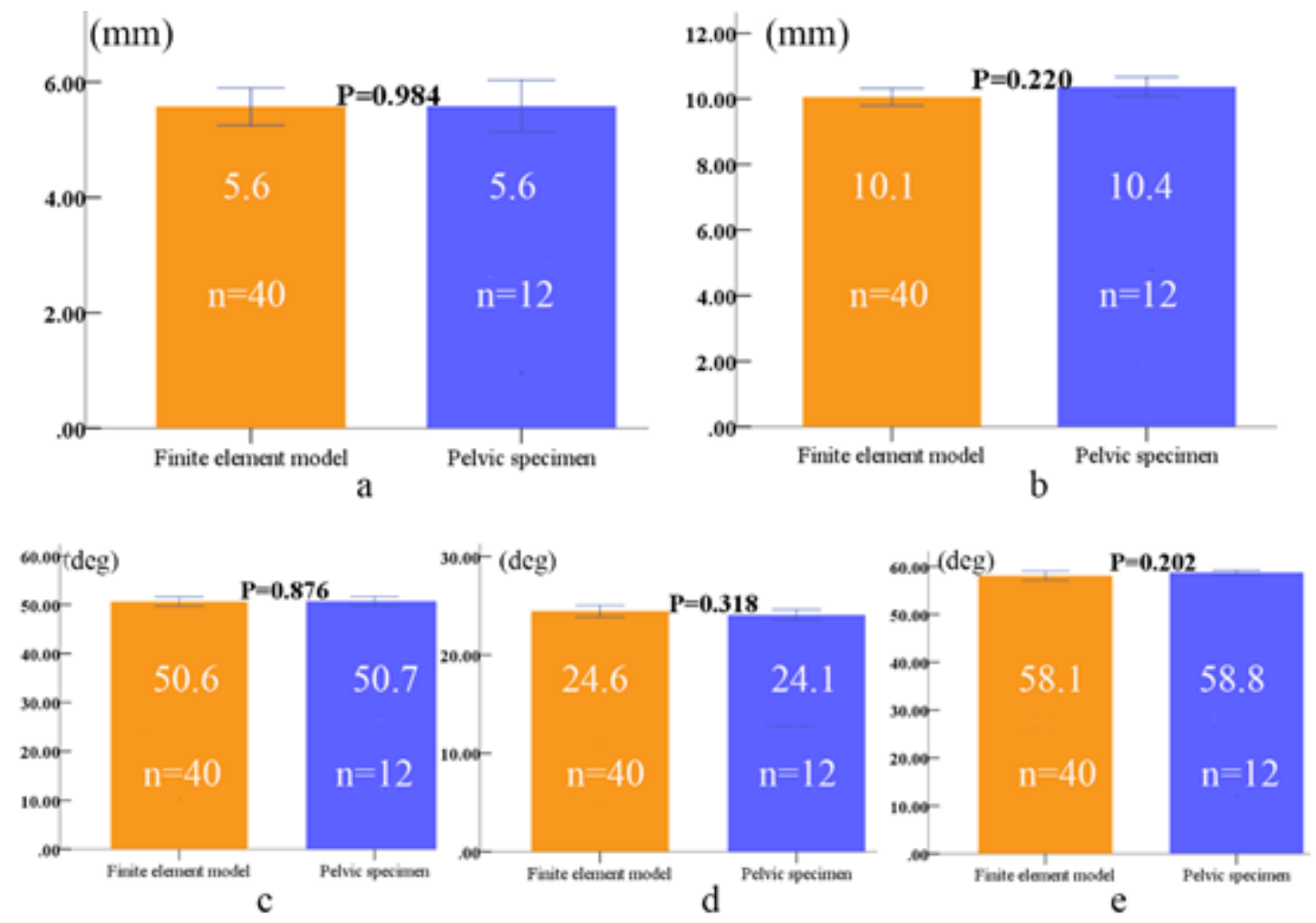

Figure 6

Comparison of parameters between finite element models analysis and pelvic specimens of females (Finite element model 40, Specimens 12); a: distance between the screw and the anterior inferior iliac spine, b: distance between screw and symphysis pubis, c: included angle between screw and coronal plane, d: included angle between screw and sagittal plane, e: included angle between screw and horizontal plane. 